\title{
Sex and age biological variation of the mandible in a Portuguese population- a forensic and medico-legal approaches with three-dimensional analysis
}

\author{
Joana Coelho $^{\text {a,c, }}$, Pedro Armelim Almiro ${ }^{b}$, Tiago Nunes ${ }^{c}$, Renata Kato ${ }^{\mathrm{d}}$, Daniela Garib ${ }^{\mathrm{e}}$, \\ António Miguéis ${ }^{\mathrm{a}}$, Ana Corte-Real ${ }^{\mathrm{c}}$ \\ ${ }^{\text {a }}$ Anatomy Institute, Faculty of Medicine, University of Coimbra, Portugal \\ ${ }^{\mathrm{b}}$ Autonomous University of Lisbon (UAL), CIP-UAL, CINEICC, Faculty of Psychology and Educational Sciences, University of Coimbra, Portugal \\ ${ }^{c}$ Forensic Dentistry Laboratory, Faculty of Medicine, University of Coimbra, Portugal \\ ${ }^{\mathrm{d}}$ Hospital for Rehabilitation of Craniofacial Anomalies, University of São Paulo, Bauru, SP, Brazil \\ e Orthodontist and Professor. Department of Orthodontics, Hospital for Rehabilitation of Craniofacial Anomalies and Bauru Dental School, University of São Paulo, \\ Bauru, SP, Brazil
}

\section{A R T I C L E I N F O}

\section{Keywords:}

Mandible

Imaging

Three-dimensional

Cone-beam computed tomography

Biological variation

Population

Forensic sciences

\begin{abstract}
A B S T R A C T
The medico-legal identification is based on a set of discriminatory characteristics between individuals in their biological, social, cultural, religious, legal and economic framework.

The purpose of this study was to characterize the biological variation, regarding gender and age, in a Portuguese population. A three-dimensional (3D) analysis of 215 mandibles (7-20 years old) from the database of the Laboratory of Forensic Dentistry, Faculty of Medicine, University of Coimbra (CE-112/2019) was performed.

A total of 13 cephalometric points defined 10 linear variables and 7 angular variables, on 3D reconstructions from ConeBeam Computed Tomography (CBCT) images. Intra and inter-observer errors were analyzed by Technical Measurement Error test. A descriptive statistics was performed. To verify the influence of gender and age on the variables and to determine its predictive value, ANOVA and Logistic Regression Analysis were performed.

Gender and age influence most of the linear variables, however, the same is not true for angular variables. In the analysis of all variables, the model has a reasonable level of sensitivity (67.8\%) according to gender. For the age prediction, with all variables, the model presented a reasonable level of sensitivity, classifying $79.4 \%$ of the individuals.

The results supported, with a high level of statistical significance, an adequate recognition of individuals highlighting the identification and criminal imputability of Portuguese individuals.
\end{abstract}

\section{Introduction}

Human identification, living or dead, has been a particularly relevant area in the field of Legal Medicine and Forensic Sciences [1,2]. The medico-legal identification is based on a set of discriminatory characteristics between individuals in their biological or clinical, social, cultural, religious, legal and economic framework [1]. It consists of a scientific process that uses specialized means with the major objective of positive identification, that is the correspondence between the information obtained and the confirmation of the individual's identity $[1,2]$. Positive identity is the best outcome in situations of missing individuals, resulting in a legal decision and the resolution of criminal investigations [1].

The identification process includes determining the biological variation of an individual, that is, the characterization of the generic parameters of identity like ancestry, sex and age. The methodology of identification can be morphological, metric or a combination of both $[3,4]$. Morphological methods result from interactions between genetic heritage, patterns of growth and development, as well as environmental influences that may differ according to the individual's sex, age and socioeconomic conditions [3-6]. For its part, the metric methods enable

\footnotetext{
* Corresponding author.

E-mail addresses: jcoelho@uc.pt (J. Coelho), paalmiro@autonoma.pt (P. Armelim Almiro), renata.mkato@gmail.com (R. Kato), dgarib@usp.br (D. Garib), amigueis@fmed.uc.pt (A. Miguéis), a.corte.real4@gmail.com (A. Corte-Real).
} 


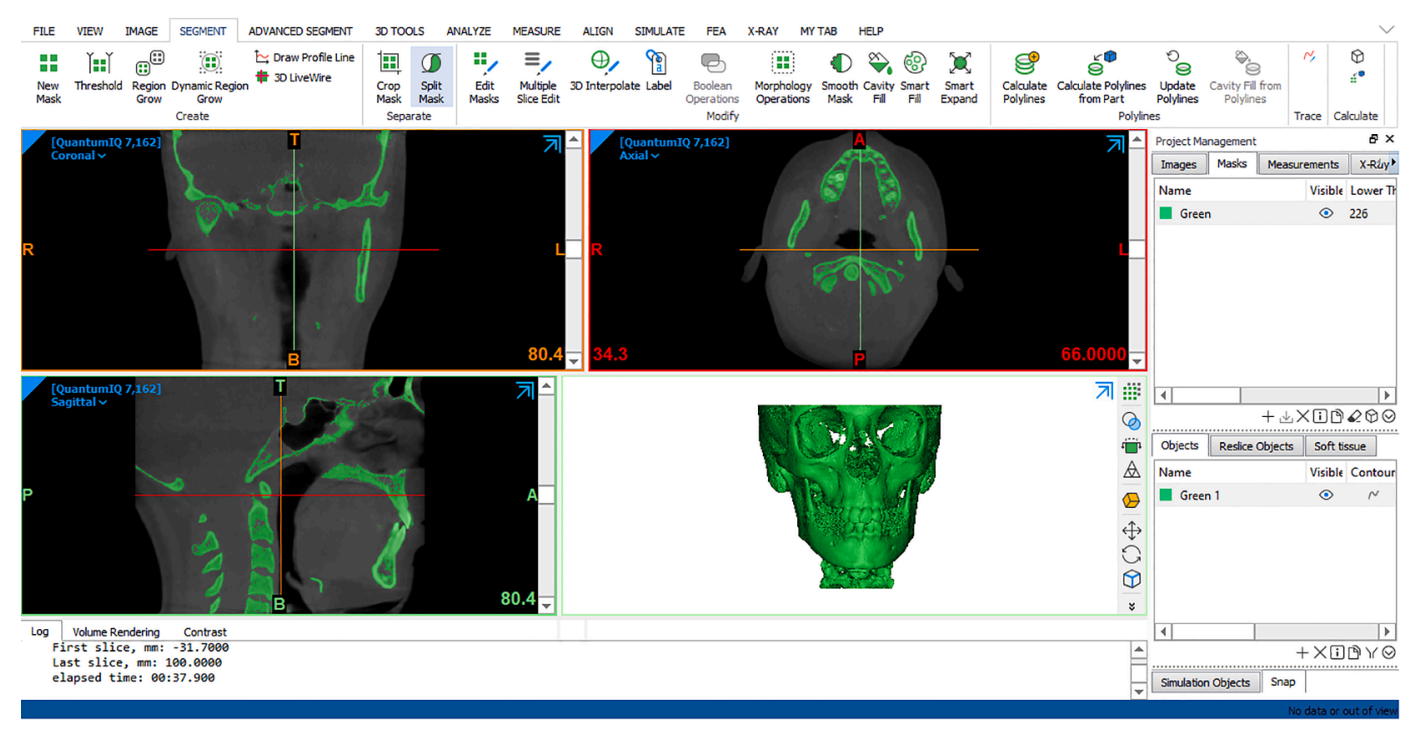

Fig. 1. 360-degree view tool to visualize the entire structure.

the mathematical analysis of correlations between parameters and thus allow to establish regression or discriminating equations between biological profiles under study [3]. Metric methods are increasingly gaining importance since they are less dependent on the observer's judgment [3-5]. In a forensic context, the comparison of ante-mortem data (AM) with post-mortem data (PM) is the method to achieve the positive identification [7-9]. Incorrect forensic identification of victims has a major impact in two contexts: those who receive the wrong remains of their loved ones and those who are never identified and their remains will never be handed over to their families [8].

The process of human identification is often only based on the analysis of the skeleton, since bones and teeth are the most resistant elements of the human body, both in archaeological contexts and in extreme forensic conditions $[4,10,11]$. The mandible is the single bone most resistant of the skeleton $[12,13]$. According to Saini and collaborators, the mandible is characterized by the presence of a dense and thick cortical bone, which makes this anatomical structure extremely resilient to external aggressions, both mechanical and chemical, which contributes to its preservation [14]. Its morphology is related to sex, age and pathologies $[12,15,16]$. Gillet et al. (2019) recently highlighted the mandible in sex determination [4] and Motawei et al. (2020) and Franklin et al (2008) refer to its usefulness in estimating age $[10,17]$. Furthermore, mandibular morphology can be used to predict subadult age with a high degree of expected accuracy [17]. The study of the mandible has been associated with several diseases and congenital anomalies [18-22], as highlighted by Giudice et al. (2018) in the Sequence of Pierre Robin [23], and by Apolloni et al. (2020) in Treacher Collins Syndrome [24].

Throughout the individual's life, the mandible changes due to age [25], associated with bone and dental development [13,26]. The mandible increases in length, due to bone deposition on the posterior surface of the ramus and concomitant compensatory resorption on the anterior surface; and in width by bone deposition on its external surface and resorption on its internal [25,27]. At birth, the mandible is the smallest bone in the skull, reaching the proportion of adult age at 12 years of age [25]. Condylar growth and remodeling are significantly influenced by local factors, notably temporomandibular joint movement and load, and are relatively immune to systemic influences such as vitamin C and D deficiency, diet and environment [13]. Considering the changes that occur in dentition throughout life, continuous adaptation of the temporomandibular joint is necessary in order to maintain the functional occlusal alignment between the upper and lower arches of the teeth: this adaptation is considered largely as a result of a continuous condylar remodeling [13].
The introduction of imaging as a complementary diagnostic test in maxillofacial surgery allowed the digital analysis of linear and angular variables of the mandible, according to Moreira et al. [18]. The study of bone development and growth, based on cephalometric analysis, was primarily performed on two-dimensional (2D) radiographic images of the skull [18-20,22]. The imaging methods of 2D analysis have been associated with the three-dimensional methods (3D) through the application of computed tomography (CT) technology [28,29]. The 3D analysis corresponds to a real visualization of the object, as an anatomical model, with a crucial role in forensic investigations and in clinical forensic medicine (orthodontic treatments, dental implants and maxillofacial surgery) [20]. The application and development of CT as a diagnostic method has been widely accepted for its precision and reduced distortion [6-9]. Three-dimensional morphometric analysis of CT scans was highlighted in diagnosis comparison studies, prior and after mandibular surgery, and according to the age range of the rehabilitation process, namely in orthopedics [30].

Cone-Beam Computed Tomography (CBCT) is associated with less radiation exposure, so in the context of the medical areas mentioned above it has obtained a prominent place $[31,32]$. The information contained in an imaging examination using tomographic technology allows its digital analysis, with fast storage and easy sharing between health professionals [6-9]. The studies by Apolloni et al. and Corte-Real et al. reveal that the information associated with $2 \mathrm{D}$ examinations is comparable with 3D examinations, as well as with examinations performed directly on dry skulls $[24,33]$.

The main objective of this study is the characterization of biological variation, through the three-dimensional analysis of mandibles of subjects in growing periods based on tomographic images obtained by CBCT.

\section{Materials and methods}

An observational, cross-sectional study was performed. It was approved by the Ethics Committee of the Faculty of Medicine of the University of Coimbra (process number CE-112/2019). 215 CBCT exams were selected from the database of the Forensic Dentistry Laboratory of the same University. Tomographic images of CBCT were obtained using i-CAT ${ }^{\circledR}$ 3D equipment (i-CAT ${ }^{\circledR}$, Imaging Sciences International, Hatfield, Pennsylvania, USA) and stored in Digital Imaging and Communications in Medicine (DICOM), with voxel size of $0.3 \mathrm{~mm}$, exposure time of $4 \mathrm{~s}$ and field of view (FOV) of 100-160 mm.

To be included in this study the individuals must have Portuguese nationality and have residency in Portugal. The CBCT should include the 


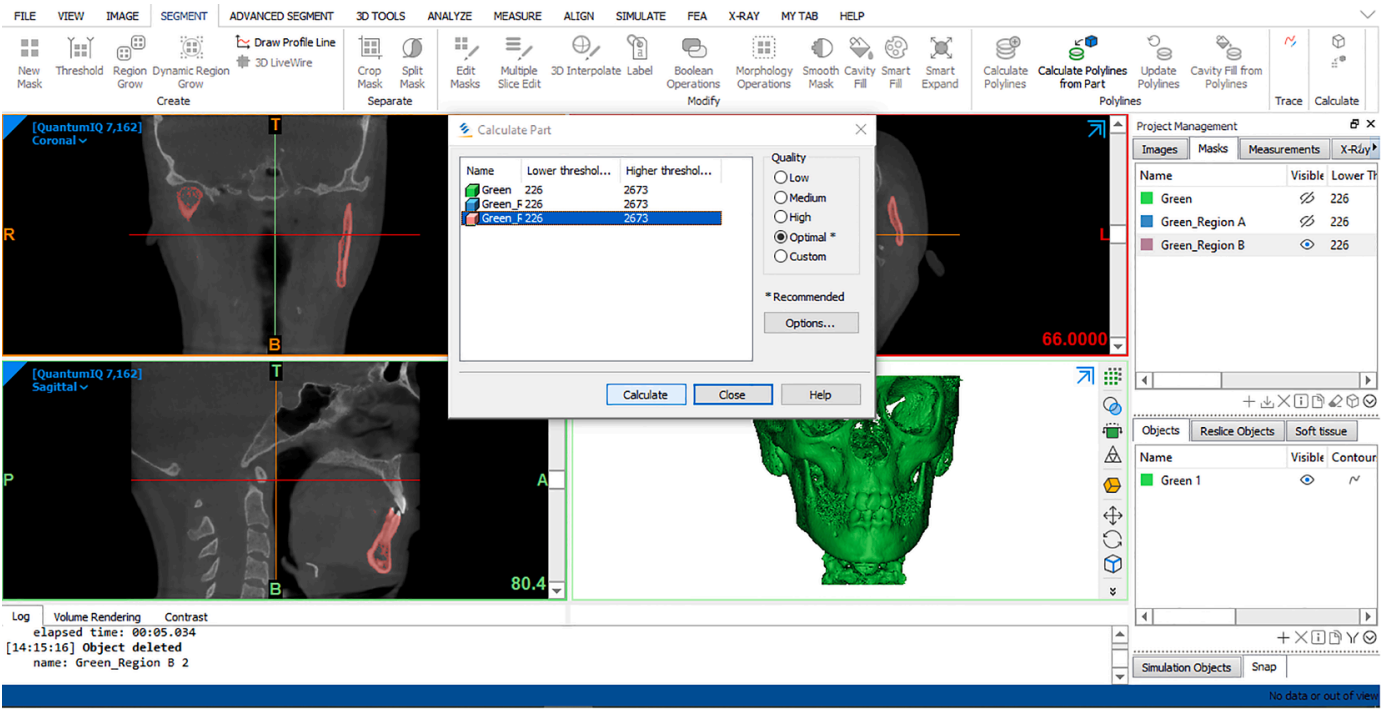

Fig. 2. Segmentation of hard tissues according to software programming, to reduce noise without reducing actual osseous anatomy.

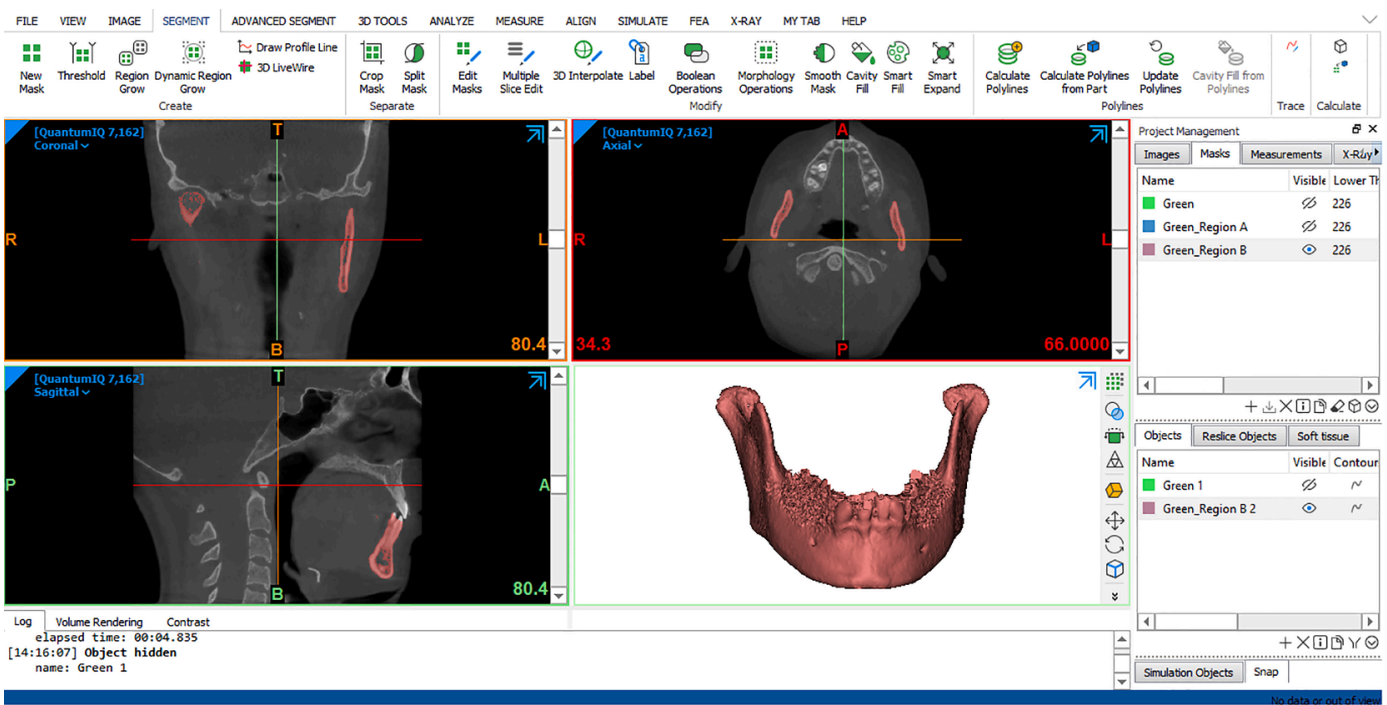

Fig. 3. 3D reconstruction for landmark identification. Mandible digitally isolated from the skull.
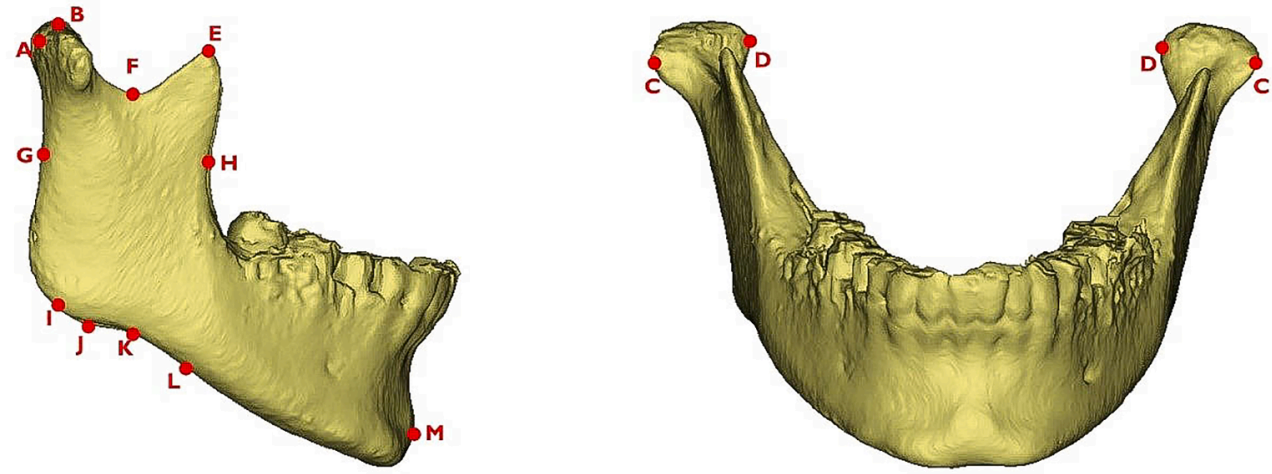

Fig. 4. Thirteen craniometric landmarks: A. Condylion; B - Superior mandible condyle; C - Lateral mandibular condylel; D - Medial mandibular condyle; E Coronoid; F - Inferior sigmoid notch; G - Posterior ramus point; H - Anterior ramus point; I - Gonion; J - Inferior gonion; K - Antegonial notch; L - Anterior convexity point; M - Gnation. 

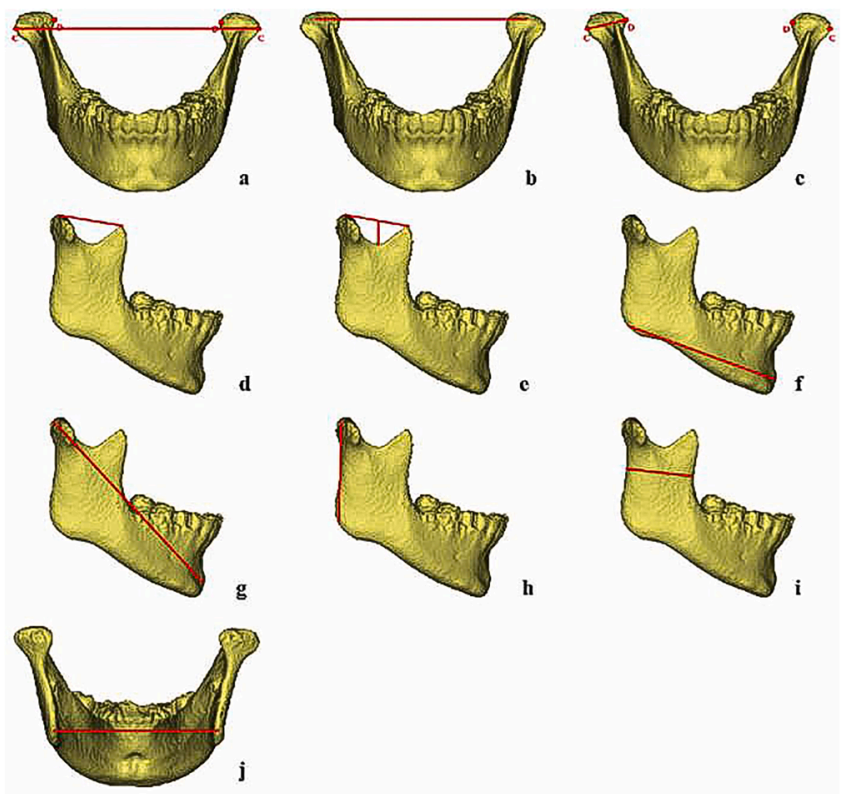

Fig. 5. 10 linear variables. a - Mandibular opening distance; b - Intercondylar distance; c - Condyle width; d - Condylion - coronoid distance; e - Mandibular notch depth; f - Mandibular body length; $g$ - Effective mandibular length; $h$ Ramus height; $\mathrm{i}$ - Ramus width; $\mathrm{j}$ - Intergonial distance.
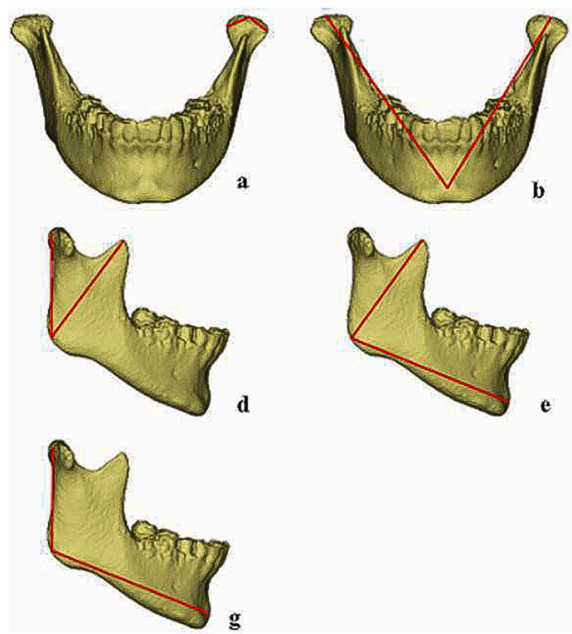

Fig. 6. 7 angular variables. a - Condylion angle; b - Intercondylar opening angle; c - Mandibular notch angle; d - Complementary angle; e - Mandibular opening angle; $\mathrm{f}$ - Antegonial notch angle; $\mathrm{g}$ - Gonial angle.

whole mandible in the exposure window. In the present study the age range selected, 7-20 years old, is in line to the subadults studies [34].

The exclusion criteria included patients with history of previous craniofacial surgical intervention and traumatological events, history of orthopedics treatment and temporomandibular disorders; history of dental rehabilitation procedure; inadequate quality of СBCT exams, including motion artifacts or excessive metal artifacts.

The team was trained before the research to ensure imaging interpretation of the mandibular anatomical details. The examiners, with imaging expertise in morphometric analysis of CBCT scans, demonstrated skills for evaluating mandibular images. Semiautomated thresholding of pixel values was performed to achieve differentiation between anatomical structures, according to the CBCT technology and Hounsfield Units (HU) measurement.
Table 1

Technical Error Measurement (TEM) analysis for intra and inter-observer error regarding linear and angular variables.

\begin{tabular}{lll}
\hline Linear variables & Intra-observer & Inter-observer \\
& TEM (\%) & TEM (\%) \\
\hline Right ramus height & 2.77 & 1.23 \\
Left ramus height & 2.70 & 1.19 \\
Right mandibular body length & 1.99 & 1.23 \\
Left mandibular body length & 1.01 & 1.24 \\
Right effective body length & 1.12 & 1.24 \\
Left effective body length & 1.19 & 1.23 \\
Right condyle width & 4.64 & 1.23 \\
Left condyle width & 4.09 & 1.31 \\
Right condylion - coronoid distance & 2.36 & 1.22 \\
Left condylion - coronoid distance & 2.26 & 1.19 \\
Intercondylar distance & 1.58 & 1.22 \\
Intergonial distance & 1.60 & 1.23 \\
Mandibular opening distance & 1.82 & 1.21 \\
Right ramus width & 3.73 & 1.20 \\
Left ramus width & 3.27 & 1.21 \\
Right mandibular notch depth & 2.50 & 1.23 \\
Left mandibular notch depth & 3.76 & 1.25 \\
Angular Variables & INTRA-OBSERVER & INTER-OBSERVER \\
& TEM (\%) & TEM (\%) \\
Right complementary angle & 3.80 & 1.19 \\
Left complementary angle & 2.65 & 1.21 \\
Right condylion angle & 2.52 & 1.33 \\
Left condylion angle & 2.17 & 1.24 \\
Intercondylar opening angle & 1.15 & 1.19 \\
Right mandibular opening angle & 1.79 & 1.23 \\
Left mandibular opening angle & 1.52 & 1.24 \\
Right mandibular notch angle & 2.73 & 1.22 \\
Left mandibular notch angle & 2.91 & 1.21 \\
Right antegonial notch angle & 2.11 & 1.23 \\
Left antegonial notch angle & 1.88 & 1.36 \\
Right gonial angle & 1.11 & 1.35 \\
Left gonial angle & 1.04 & \\
\hline & & \\
& & \\
& &
\end{tabular}

Three evaluations of each mandible were performed separately by three observers at three different times with a minimum of 7 day- interval. The observers were permitted to access all files of each exam to ensure all cranium information and to improve the visualization of landmarks.

CBCT were imported into Mimics Innovation Suite 17.0 software (Materialise, Leuven, Belgium) and reconstructed to generate 3D craniofacial images. The software allowed the 360-degree view tool to visualize the entire structure and the option to refine the position by moving the landmark point across the length of the reconstruction contributed to its use (Figs. 1-3).

For obtaining a suitable 3D reconstruction for landmark identification, the steps required to process the image included segmentation of hard (bone and tooth) tissues according to software programming, slice by slice edition to reduce noise without reducing actual osseous anatomy and segmentation revision to verify the presence of the major contour line of the mandible in axial, frontal and sagittal views. The mandible of each patient was digitally isolated from the skull and right and left sides were separately analyzed.

Thirteen chosen landmarks (Fig. 4) were selected and seventeen measures were demarcated in the three-dimensional reconstruction to evaluate the mandibular condyle, ramus and body, highlighted by Corte-Real [33]. From the measures, 10 linear variables and 7 angular variables were performed (Figs. 5 and 6). It attempted to use landmarks already used in previous mandibular assessments [31-33,35] to allow transitions from 2D to 3D Methodologies and comparisons with existing databases [20]. No new craniometric landmarks were suggested, however, new measurements were obtained with the objective to perform a complete mandibular assessment. The selected landmarks and measurements can provide valuable information for mandibular assessment, complementary or as an alternative for the objectives, in extreme forensic situations [33]. 
Table 2

Means (M) and standard deviation (SD) regarding linear variables by gender and age group (7-15 years old) and (16-20 years old).

\begin{tabular}{|c|c|c|c|c|c|c|c|c|c|c|c|c|}
\hline & \multicolumn{6}{|c|}{ MASCULINE } & \multicolumn{6}{|c|}{ FEMININE } \\
\hline & \multicolumn{2}{|l|}{$(7-15)$} & \multicolumn{2}{|l|}{$(16-20)$} & \multicolumn{2}{|l|}{$\mathrm{N}$} & \multicolumn{2}{|l|}{$(7-15)$} & \multicolumn{2}{|l|}{$(16-20)$} & \multicolumn{2}{|l|}{$\mathrm{N}$} \\
\hline & M & SD & M & SD & M & SD & M & SD & M & SD & M & DP \\
\hline Right ramus height & 52.8 & 7.18 & 58.07 & 5.4 & 52.96 & 7.13 & 51.43 & 5.59 & 53.76 & 4.93 & 51.31 & 5.55 \\
\hline Left ramus height & 52.46 & 7.41 & 58.61 & 5.18 & 52.64 & 7.35 & 51.03 & 5.38 & 53.02 & 4.75 & 50.87 & 5.34 \\
\hline Right mandibular body length & 83.2 & 8.16 & 89.33 & 5.41 & 83.35 & 8.12 & 80.61 & 6.3 & 83.26 & 5.28 & 80.47 & 6.21 \\
\hline Left mandibular body length & 82.91 & 8.17 & 88.49 & 5.49 & 83.1 & 8.13 & 80.15 & 6.32 & 82.83 & 5.19 & 80.02 & 6.24 \\
\hline Right effective body length & 117.86 & 10.32 & 125.96 & 7.13 & 118.1 & 11.29 & 114.38 & 8.62 & 118.3 & 7.21 & 114.2 & 8.46 \\
\hline Left effective body length & 116.51 & 10.36 & 125.81 & 7.32 & 116.7 & 12.32 & 113.15 & 8.66 & 117.79 & 6.65 & 112.9 & 12.51 \\
\hline Right condyle width & 17.42 & 8.19 & 20.92 & 3.35 & 17.45 & 8.15 & 16.66 & 8.18 & 16.93 & 2.05 & 16.65 & 8.14 \\
\hline Left condyle width & 17.55 & 8.24 & 21.26 & 3.29 & 17.58 & 8.20 & 16.62 & 8.02 & 16.79 & 2.02 & 16.6 & 7.98 \\
\hline Right condylion - coronoid distance & 34.46 & 3.55 & 35.85 & 3.2 & 34.51 & 3.54 & 33.1 & 3.45 & 34.18 & 2.71 & 33.06 & 3.41 \\
\hline Left condylion - coronoid distance & 35.42 & 7.21 & 36.32 & 3.57 & 35.48 & 7.18 & 33.25 & 3.54 & 34.5 & 3.14 & 33.21 & 3.49 \\
\hline Intercondylar distance & 97.36 & 6.36 & 101.36 & 6.36 & 97.55 & 6.53 & 95.75 & 6.57 & 98.01 & 5.86 & 95.58 & 6.31 \\
\hline Intergonial distance & 87.47 & 7.59 & 91.83 & 6.33 & 87.59 & 7.57 & 84.98 & 5.54 & 86.75 & 4.83 & 84.88 & 5.44 \\
\hline Mandibular opening distance & 109.52 & 7.86 & 115.53 & 4.58 & 109.7 & 8.02 & 107.17 & 7.29 & 109.75 & 6.03 & 107 & 7.00 \\
\hline Right ramus width & 31.42 & 3.3 & 32.6 & 3.1 & 31.44 & 3.28 & 30.18 & 3.41 & 30.78 & 3.3 & 30.16 & 3.40 \\
\hline Left ramus width & 32.36 & 7.31 & 32.99 & 3.32 & 32.38 & 7.27 & 30.23 & 3.48 & 30.76 & 3.31 & 30.21 & 3.46 \\
\hline Right mandibular notch depth & 12.77 & 2.14 & 12.77 & 2.12 & 12.78 & 2.12 & 12.41 & 2.14 & 12.92 & 2.11 & 12.4 & 2.14 \\
\hline Left mandibular notch depth & 13.08 & 2.04 & 13.89 & 1.92 & 13.01 & 2.04 & 12.57 & 1.9 & 13.14 & 1.66 & 12.58 & 1.89 \\
\hline
\end{tabular}

Table 3

Analysis of variance in relation to gender and age for linear variables, regarding the statistical parameters $(F, \mathrm{df}$ and $p)$.

\begin{tabular}{llll}
\hline Gender & $F$ & $\mathrm{df}$ & $p$ \\
\hline Right ramus height & $14.582^{* * *}$ & 1 & 0.000 \\
Left ramus height & $17.361^{* * *}$ & 1 & 0.000 \\
Right mandibular body length & $25.661^{* * *}$ & 1 & 0.000 \\
Left mandibular body length & $24.521^{* * *}$ & 1 & 0.000 \\
Right effective body length & $24.344^{* * *}$ & 1 & 0.000 \\
Left effective body length & $12.181^{* *}$ & 1 & 0.001 \\
Right condyle width & $2.116^{*}$ & 1 & 0.147 \\
Left condyle width & 2.743 & 1 & 0.099 \\
Right condylion - coronoid distance & $14.946^{* * *}$ & 1 & 0.000 \\
Left condylion - coronoid distance & $10.529^{* *}$ & 1 & 0.001 \\
Intercondylar distance & $12.772^{* * *}$ & 1 & 0.000 \\
Intergonial distance & $19.777^{* * *}$ & 1 & 0.000 \\
Mandibular opening distance & $19.970^{* * *}$ & 1 & 0.000 \\
Right ramus width & $11.197^{* *}$ & 1 & 0.001 \\
Left ramus width & $8.951^{* *}$ & 1 & 0.003 \\
Right mandibular notch depth & $4.401^{*}$ & 1 & 0.037 \\
Left mandibular notch depth & $8.660^{* *}$ & 1 & 0.004 \\
Age & $F$ & $\mathrm{df}$ & $p$ \\
Right ramus height & $68.060^{* * *}$ & 1 & 0.000 \\
Left ramus height & $76.655^{* * *}$ & 1 & 0.000 \\
Right mandibular body length & $72.545^{* * *}$ & 1 & 0.000 \\
Left mandibular body length & $62.115^{* * *}$ & 1 & 0.000 \\
Right effective body length & $72.927^{* * *}$ & 1 & 0.000 \\
Left effective body length & $45.199^{* * *}$ & 1 & 0.000 \\
Right condyle width & $6.414^{*}$ & 1 & 0.012 \\
Left condyle width & $6.744^{*}$ & 1 & 0.010 \\
Right condylion - coronoid distance & $22.349^{* * *}$ & 1 & 0.000 \\
Left condylion - coronoid distance & $6.899^{* *}$ & 1 & 0.009 \\
Intercondylar distance & $46.127^{* * *}$ & 1 & 0.000 \\
Intergonial distance & $37.139^{* * *}$ & 1 & 0.000 \\
Mandibular opening distance & $61.403^{* * *}$ & 1 & 0.000 \\
Right ramus width & $10.507^{* *}$ & 1 & 0.001 \\
Left ramus width & 1.965 & 1 & 0.162 \\
Right mandibular notch depth & $15.797^{* * *}$ & 1 & 0.000 \\
Left mandibular notch depth & $21.875^{* * *}$ & 1 & 0.000 \\
\hline & & &
\end{tabular}

Legend: $* * * \mathrm{p}<.001$.

$* * \mathrm{p}<.01$.

${ }^{*} \mathrm{p}<.05$.

\subsection{Statistical analysis}

For intra and inter-examiner error analysis, the mandibles were remeasured three times by three examiners after a minimum 7-day interval. Intra and inter-observer error was calculated with Technical Error of Measurement (TEM) [35]. The parametric ANOVA test was used to verify the influence of sex and age on the variables (linear and angular); The Logistic Regression Analysis was used to determine the predictive variables in relation to sex and age. The value of statistical significance was set at least $\mathrm{p}<.05$ [36]. The analyses were performed using IBM SPSS for Windows (Statistical Package for the Social Sciences) [35,36].

\section{Results}

Two hundred and fifteen reports were selected. Table 1 show the intra and inter-observer error for linear and angular variables. Excellent intra and inter-observer errors were found for all variables. Acceptable errors were found for the evaluated variables [35].

\subsection{Linear variables}

Table 2 shows the mean values and standard deviation analyzed by sex and age and Table 3 shows the sex and age influence, respectively, on the linear variables.

It was possible to notice that sex has an influence on most linear variables except for the condylar dimension. The age groups also influence most of the linear variables, except for the width of the left ramus.

\subsection{Angular variables}

Table 4 shows the mean values and standard deviation analyzed by sex and age. Table 5 present the sex and age influence, respectively, on the angular variables.

Sex only influences the condylar angles. The age groups only influence the complementary angles, left condylar angle and right gonial angle.

\subsection{Logistic regression analysis}

In the analysis of all variables (linear and angular) for sex prediction, a total adjusted model was obtained based on the Omnibus test $[\chi 2$ (30) $=50,058, p=.012$ ] (significant, $p<.05$ ) and the Homer and Lemershow test $[\chi 2(8)=12,997, p=.112]$ (not significant $p>.05$ ), which explains between 20.9\% (Cox \& Snell R square) and 27.8\% (Nagelkerke R square) of the variance of results, suggesting that the model has a reasonable level of sensitivity, considering that it adequately classifies $67.8 \%$ of individuals according to sex.

Table 6 shows the logistic regression analysis with all variables, linear and angular, for sex prediction. 
Means (M) and standard deviation (SD) regarding angular variables by gender and age group (7-15 years old) and (16-20 years old).

\begin{tabular}{|c|c|c|c|c|c|c|c|c|c|c|c|c|}
\hline & \multicolumn{6}{|c|}{ Masculine } & \multicolumn{6}{|c|}{ feminine sex } \\
\hline & \multicolumn{2}{|l|}{$(7-15)$} & \multicolumn{2}{|l|}{$(16-20)$} & \multicolumn{2}{|l|}{$\mathrm{N}$} & \multicolumn{2}{|l|}{$(7-15)$} & \multicolumn{2}{|l|}{$(16-20)$} & \multicolumn{2}{|l|}{$\mathrm{N}$} \\
\hline & M & SD & M & SD & M & SD & M & SD & M & SD & M & SD \\
\hline Right complementary angle & 37.38 & 4.71 & 34.68 & 4.3 & 37.36 & 4.68 & 36.85 & 4.01 & 36.42 & 3.05 & 36.87 & 4.01 \\
\hline Left complementary angle & 37.92 & 4.69 & 35.04 & 4.39 & 37.89 & 4.65 & 37.25 & 4.24 & 37.22 & 4.21 & 37.28 & 4.24 \\
\hline Right condylion angle & 115.09 & 12.47 & 118.62 & 11.69 & 115.2 & 12.4 & 109.16 & 11.59 & 110.96 & 11.65 & 110 & 11.49 \\
\hline Left condylion angle & 109.92 & 12.22 & 115.13 & 12.18 & 109.9 & 12.17 & 108.39 & 10.42 & 127.15 & 9.73 & 116.9 & 11.69 \\
\hline Intercondylar opening angle & 57.48 & 4.23 & 56.71 & 3.73 & 57.46 & 4.20 & 58.18 & 3.95 & 57.81 & 3.4 & 58.2 & 3.95 \\
\hline Right mandibular opening angle & 86.11 & 6 & 85.22 & 6.17 & 86.04 & 5.97 & 86.14 & 6.23 & 85.37 & 6.09 & 86.21 & 6.21 \\
\hline Left mandibular opening angle & 85.45 & 5.56 & 84.81 & 5.95 & 85.37 & 5.49 & 85.71 & 6.33 & 84.99 & 6.45 & 85.79 & 6.33 \\
\hline Right mandibular notch angle & 108.11 & 8.92 & 107.05 & 8.81 & 108.1 & 8.88 & 107.53 & 9.55 & 106.84 & 8.25 & 107.5 & 9.5 \\
\hline Left mandibular notch angle & 108.61 & 8.87 & 107.21 & 9.04 & 108.6 & 8.89 & 108.07 & 8.96 & 108 & 7.98 & 107 & 8.86 \\
\hline Right antegonial notch angle & 164.57 & 6.18 & 162.78 & 7.13 & 164.6 & 6.16 & 195.1 & 7.14 & 164.58 & 6.84 & 178.3 & 6.91 \\
\hline Left antegonial notch angle & 165.73 & 6.79 & 164.91 & 7.81 & 165.7 & 6.73 & 165.41 & 7.25 & 166.13 & 6.73 & 165.4 & 7.24 \\
\hline Right gonial angle & 118.92 & 6 & 116.13 & 6.02 & 118.9 & 5.94 & 118.65 & 5.61 & 117.82 & 5.35 & 118.7 & 5.61 \\
\hline Left gonial angle & 118.23 & 6.01 & 116.21 & 5.3 & 118.1 & 7.92 & 119.36 & 5.71 & 118.95 & 5.9 & 119.4 & 5.73 \\
\hline
\end{tabular}

Table 5

Analysis of variance in relation to gender and age for angular variables, regarding the statistical parameters $(F, \mathrm{df}$ and $p)$.

\begin{tabular}{llll}
\hline Gender & $F$ & df & $p$ \\
\hline Right complementary angle & 0.126 & 1 & 0.723 \\
Left complementary angle & 0.009 & 1 & 0.927 \\
Right condylion angle & $11.678^{* *}$ & 1 & 0.001 \\
Left condylion angle & $4.154^{*}$ & 1 & 0.043 \\
Intercondylar opening angle & 2.686 & 1 & 0.103 \\
Right mandibular opening angle & 0.138 & 1 & 0.710 \\
Left mandibular opening angle & 0.328 & 1 & 0.567 \\
Right mandibular notch angle & 0.030 & 1 & 0.863 \\
Left mandibular notch angle & 0.013 & 1 & 0.911 \\
Right antegonial notch angle & 0.134 & 1 & 0.714 \\
Left antegonial notch angle & 0.072 & 1 & 0.789 \\
Right gonial angle & 0.432 & 1 & 0.512 \\
Left gonial angle & 1.579 & 1 & 0.210 \\
Age & $F$ & $\mathrm{df}$ & $p$ \\
Right complementary angle & $17.882^{* * *}$ & 1 & 0.000 \\
Left complementary angle & $12.827^{* * *}$ & 1 & 0.000 \\
Right condylion angle & 2.026 & 1 & 0.156 \\
Left condylion angle & $7.692^{* *}$ & 1 & 0.006 \\
Intercondylar opening angle & 2.950 & 1 & 0.087 \\
Right mandibular opening angle & 2.989 & 1 & 0.085 \\
Left mandibular opening angle & 2.214 & 1 & 0.138 \\
Right mandibular notch angle & 1.399 & 1 & 0.238 \\
Left mandibular notch angle & 0.827 & 1 & 0.364 \\
Right antegonial notch angle & 1.657 & 1 & 0.199 \\
Left antegonial notch angle & 0.070 & 1 & 0.792 \\
Right gonial angle & $14.072^{* * *}$ & 1 & 0.000 \\
Left gonial angle & 2.133 & 1 & 0.146 \\
\hline
\end{tabular}

Legend: ** $\mathrm{p}<.001$.

$* * \mathrm{p}<.01$.

$* \mathrm{p}<.05$.

In the analysis of all variables (linear and angular) to predict age, a model (M1) adjusted based on the Omnibus test $[\chi 2(30)=106,748, p=$ .000] (significant, $p<.001$ ) was obtained and in the Hosmer and Lemershow test $[\chi 2(8)=3.034, p=.932]$ (not significant, $p>.05$ ), which explains between $39.3 \%$ (Cox \& Snell R square) and $52.6 \%$ (Nagelkerke R square) of the variance of the results suggesting that the model has a reasonable level of sensitivity considering that the referred model adequately classifies $79.4 \%$ of the individuals according to the age group.

Table 7 shows the logistic regression analysis with all variables, linear and angular, to predict age.

Table 8 shows the logistic regression analysis with 3 different models to determine the predictive value of the variables, considering different combinations, according to the age groups (M2, M3 and M4).

\section{Discussion}

The methodologies of sex and age analysis have been adapted to the technologies available by the scientific community. The new 3D technologies allowed to overcome the disadvantages of overlapping anatomical structures and artifacts associated with $2 \mathrm{D}$ analysis, highlighted by Liberton et al., in 2019 [16].

In the present study, the age range selected intends to complement Franklin's study (2008) [17] with 2D images. This age group corresponds to the average period of life that precedes medical interventions, orthodontic-orthopedic (12 to 13 years old, at growth spurt, in Angle's Class II and 7 to 9 years old in skeletal Angle Class III) and orthodonticsurgical treatment (after skeletal maturity) [37]. Once the variables were evaluated at an age range when changes arising from growth occur, 2 age subgroups (7-15 years old and 16-20 years old) were studied to validate the method at this population sample. On the other hand, it was a population integrated in a pre-school and school program with guidelines for regular education in the context of diet and environment [38].

In this study, the authors included linear and angular measurements widely used in $2 \mathrm{D}$ analysis, which supported the diagnosis of serious pathologies. The variables: ramus height, gonial angle, intergonial distance, effective mandibular length and condyle width as well as the analysis of both sides, right and left in a 3D analysis of the sample, were referenced by Lopes da Silva (2008), Chang (2012), Silva (2018), Giudice (2018 and 2019), with relevant application in mandibular asymmetries at young ages and in the STC and SPR diagnosis [23,39-42]. Mandibular asymmetries at young ages are related to changes in condylar morphology, and the 3D analysis of this mandibular structure is highlighted in the present study [43]. The morphological evaluation of the mandible can provide a comparison between data which can lead to a positive identification [33].

The intra and inter-observer error was acceptable in all linear and angular variables, which confirms the accuracy of the method reported by Corte-Real et al. (2020) [33].

Few studies reported the influence of sex in craniometrics characteristics in relation to a population under 20 years old, focused on a 3D analysis, and nonexistent in the left and right portions of the mandible. Fan et al. (2019) studied sexual dimorphism in relation to the shape and size of the mandible in 3D reconstructions in a sample of Australian children between 8.5 and 19.5 years of age, revealing that there has been a sexual dimorphism since the age of 9 in the size of this skull bone [44]. By analogy with the variables of the present study, we highlight the studies of Amina et al. (2014), Tunis et al. (2017), Yuvashree et al. (2018) and Gillet et al. (2019) safeguarding the fact that they considered a population $>20$ years of age. In all studies the mean values for males are significantly higher than for females, except for the gonial 
Table 6

Logistic regression analysis with all variables (linear and angular) for gender, regarding the statistical parameters, with Confidence Interval (CI) 95\%.

\begin{tabular}{|c|c|c|c|c|c|c|c|c|}
\hline & \multicolumn{8}{|c|}{ MODEL FOR GENDER } \\
\hline & \multirow[t]{2}{*}{ Variables } & \multirow[b]{2}{*}{$p$} & \multirow[b]{2}{*}{$\operatorname{Exp}(B)$} & \multicolumn{2}{|l|}{ Sumary } & \multirow[t]{2}{*}{ Hosmer And Lemeshow Test } & \multicolumn{2}{|c|}{ 95\% CI.for EXP(B) } \\
\hline & & & & Cox \& Snell R Square & Nagelkerke R Square & & Lower & Upper \\
\hline Right ramus height & $\mathrm{X}$ & 0.245 & 0.763 & 0.209 & 0.278 & 0.112 & 0.484 & 1.204 \\
\hline Left ramus height & $\mathrm{X}$ & 0.588 & 1.064 & & & & 0.851 & 1.330 \\
\hline Right mandibular body length & $\mathrm{X}$ & 0.331 & 0.770 & & & & 0.454 & 1.305 \\
\hline Left mandibular body length & $\mathrm{X}$ & 0.908 & 1.016 & & & & 0.780 & 1.322 \\
\hline Right effective body length & $\mathrm{X}$ & 0.551 & 1189 & & & & 0.673 & 2.099 \\
\hline Left effective body length & $\mathrm{X}$ & 0.495 & 0.960 & & & & 0.852 & 1.081 \\
\hline Right condyle width & $\mathrm{X}$ & 0.488 & 1.097 & & & & 0.845 & 1.423 \\
\hline Left condyle width & $\mathrm{X}$ & 0.501 & 0.913 & & & & 0.701 & 1.189 \\
\hline Right condylion - coronoid distance & $\mathrm{X}$ & 0.497 & 1.164 & & & & 0.751 & 1.805 \\
\hline Left condylion - coronoid distance & $\mathrm{X}$ & 0.453 & 0.914 & & & & 0.724 & 1.155 \\
\hline Intercondylar distance & $\mathrm{X}$ & 0.177 & 0.892 & & & & 0.755 & 1.053 \\
\hline Intergonial distance & $\mathrm{X}$ & 0.342 & 1.054 & & & & 0.946 & 1.175 \\
\hline Mandibular opening distance & $\mathrm{X}$ & 0.274 & 1.151 & & & & 0.895 & 1.480 \\
\hline Right ramus width & $\mathrm{X}$ & 0.087 & 1.359 & & & & 0.956 & 1.930 \\
\hline Left ramus width & $\mathrm{X}$ & 0.009 & 0.630 & & & & 0.445 & 0.893 \\
\hline Right mandibular notch depth & $\mathrm{X}$ & 0.395 & 1.243 & & & & 0.753 & 2.052 \\
\hline Left mandibular notch depth & $\mathrm{X}$ & 0.307 & 0.768 & & & & 0.462 & 1.275 \\
\hline Right complementary angle & $\mathrm{X}$ & 0.296 & 0.818 & & & & 0.562 & 1.192 \\
\hline Left complementary angle & $\mathrm{X}$ & 0.103 & 0.734 & & & & 0.506 & 1.065 \\
\hline Right condylion angle & $\mathrm{X}$ & 0.009 & 0.954 & & & & 0.921 & 0.988 \\
\hline Left condylion angle & $\mathrm{X}$ & 0.850 & 0.996 & & & & 0.961 & 1.034 \\
\hline Intercondylar opening angle & $\mathrm{X}$ & 0.359 & 0.834 & & & & 0.566 & 1.229 \\
\hline Right mandibular opening angle & $\mathrm{X}$ & 0.787 & 0.959 & & & & 0.711 & 1.295 \\
\hline Left mandibular opening angle & $\mathrm{X}$ & 0.019 & 0.669 & & & & 0.478 & 0.935 \\
\hline Right mandibular notch angle & $\mathrm{X}$ & 0.869 & 0.991 & & & & 0.895 & 1.098 \\
\hline Left mandibular notch angle & $\mathrm{X}$ & 0.630 & 1.023 & & & & 0.931 & 1.125 \\
\hline Right antegonial notch angle & $\mathrm{X}$ & 0.954 & 1.002 & & & & 0.942 & 1.065 \\
\hline Left antegonial notch angle & $\mathrm{X}$ & 0.755 & 0.991 & & & & 0.933 & 1.051 \\
\hline Right gonial angle & $\mathrm{X}$ & 0.413 & 0.828 & & & & 0.528 & 1.300 \\
\hline Left gonial angle & $\mathrm{X}$ & 0.011 & 1.539 & & & & 1.103 & 2.147 \\
\hline
\end{tabular}

Table 7

Logistic regression analysis (M1) with all variables (linear and angular) for age, regarding the statistical parameters, with Confidence Interval (CI) 95\%.

\begin{tabular}{|c|c|c|c|c|c|c|c|c|}
\hline & \multicolumn{8}{|l|}{ MODEL 1} \\
\hline & \multirow[t]{2}{*}{ Variables } & \multirow[b]{2}{*}{$p$} & \multirow[b]{2}{*}{$\operatorname{Exp}(B)$} & \multicolumn{2}{|l|}{ Sumary } & \multirow[t]{2}{*}{ Hosmer And Lemeshow Test } & \multicolumn{2}{|c|}{ 95\% CI.for $\operatorname{EXP}(\mathrm{B})$} \\
\hline & & & & Cox \& Snell R Square & Nagelkerke R Square & & Lower & Upper \\
\hline Right ramus height & $\mathrm{X}$ & 0.421 & 0.765 & 0.393 & 0.526 & 0.932 & 0.398 & 1.469 \\
\hline Left ramus height & $\mathrm{X}$ & 0.325 & 1.23 & & & & 0.809 & 1.894 \\
\hline Right mandibular body length & $\mathrm{X}$ & 0.953 & 1.02 & & & & 0.489 & 2.137 \\
\hline Left mandibular body length & $\mathrm{X}$ & 0.898 & 1.02 & & & & 0.690 & 1.528 \\
\hline Right effective body length & $\mathrm{X}$ & 0.352 & 1.45 & & & & 0.662 & 3.182 \\
\hline Left effective body length & $\mathrm{X}$ & 0.968 & 1.00 & & & & 0.724 & 1.399 \\
\hline Right condyle width & $\mathrm{X}$ & 0.742 & 1.05 & & & & 0.779 & 1.421 \\
\hline Left condyle width & $\mathrm{X}$ & 0.600 & 0.922 & & & & 0.679 & 1.251 \\
\hline Right condylion - coronoid distance & $\mathrm{X}$ & 0.176 & 1.53 & & & & 0.825 & 2.867 \\
\hline Left condylion - coronoid distance & $\mathrm{X}$ & 0.823 & 0.943 & & & & 0.567 & 1.569 \\
\hline Intercondylar distance & $\mathrm{X}$ & 0.450 & 0.928 & & & & 0.764 & 1.127 \\
\hline Intergonial distance & $\mathrm{X}$ & 0.623 & 1.03 & & & & 0.906 & 1.178 \\
\hline Mandibular opening distance & $\mathrm{X}$ & 0.095 & 0.775 & & & & 0.574 & 1.045 \\
\hline Right ramus width & $\mathrm{X}$ & 0.629 & 1.10 & & & & 0.740 & 1.644 \\
\hline Left ramus width & $\mathrm{X}$ & 0.083 & 0.702 & & & & 0.471 & 1.048 \\
\hline Right mandibular notch depth & $\mathrm{X}$ & 0.479 & 0.805 & & & & 0.442 & 1.468 \\
\hline Left mandibular notch depth & $\mathrm{X}$ & 0.898 & 1.04 & & & & 0.550 & 1.978 \\
\hline Right complementary angle & $\mathrm{X}$ & 0.062 & 0.619 & & & & 0.374 & 1.025 \\
\hline Left complementary angle & $\mathrm{X}$ & 0.815 & 1.06 & & & & 0.653 & 1.720 \\
\hline Right condylion angle & $\mathrm{X}$ & 0.356 & 0.980 & & & & 0.939 & 1.023 \\
\hline Left condylion angle & $\mathrm{X}$ & 0.046 & 1.04 & & & & 1.001 & 1.100 \\
\hline Intercondylar opening angle & $\mathrm{X}$ & 0.009 & 1.87 & & & & 1.170 & 3.013 \\
\hline Right mandibular opening angle & $\mathrm{X}$ & 0.866 & 0.969 & & & & 0.675 & 1.392 \\
\hline Left mandibular opening angle & $\mathrm{X}$ & 0.342 & 0.827 & & & & 0.559 & 1.223 \\
\hline Right mandibular notch angle & $\mathrm{X}$ & 0.578 & 0.964 & & & & 0.847 & 1.097 \\
\hline Left mandibular notch angle & $\mathrm{X}$ & 0.951 & 1.00 & & & & 0.880 & 1.145 \\
\hline Right antegonial notch angle & $\mathrm{X}$ & 0.212 & 0.954 & & & & 0.886 & 1.027 \\
\hline Left antegonial notch angle & $\mathrm{X}$ & 0.970 & 1.00 & & & & 0.930 & 1.078 \\
\hline Right gonial angle & $\mathrm{X}$ & 0.561 & 0.836 & & & & 0.456 & 1.530 \\
\hline Left gonial angle & $\mathrm{X}$ & 0.221 & 1.31 & & & & 0.850 & 2.018 \\
\hline
\end{tabular}


Table 8

Logistic regression analysis (M2, M3 and M4) for different combinations of variables, regarding the statistical parameters, with Confidence Interval (CI) 95\%.

\begin{tabular}{|c|c|c|c|c|c|c|c|c|c|c|c|c|c|c|c|c|c|c|}
\hline & \multicolumn{6}{|l|}{ MODEL 2} & \multicolumn{6}{|l|}{ MODEL 3} & \multicolumn{6}{|l|}{ MODEL 4} \\
\hline & \multirow[t]{2}{*}{ Variáveis } & \multicolumn{2}{|l|}{ Sumary } & \multirow{2}{*}{$\begin{array}{l}\text { Hosmer And } \\
\text { Lemeshow Test }\end{array}$} & \multirow[t]{2}{*}{$p$} & \multirow{2}{*}{$\begin{array}{l}\text { Exp } \\
\text { (B) }\end{array}$} & \multirow[t]{2}{*}{ Variáveis } & \multicolumn{2}{|l|}{ Sumary } & \multirow{2}{*}{$\begin{array}{l}\text { Hosmer And } \\
\text { Lemeshow Test }\end{array}$} & \multirow[t]{2}{*}{$p$} & \multirow{2}{*}{$\begin{array}{l}\text { Exp } \\
\text { (B) }\end{array}$} & \multirow[t]{2}{*}{ Variáveis } & \multicolumn{2}{|l|}{ Sumary } & \multirow{2}{*}{$\begin{array}{l}\text { Hosmer And } \\
\text { Lemeshow Test }\end{array}$} & \multirow[t]{2}{*}{$p$} & \multirow{2}{*}{$\begin{array}{l}\text { Exp } \\
\text { (B) }\end{array}$} \\
\hline & & $\begin{array}{l}\text { Cox \& } \\
\text { Snell R } \\
\text { Square }\end{array}$ & $\begin{array}{l}\text { Nagelkerke R } \\
\text { Square }\end{array}$ & & & & & $\begin{array}{l}\text { Cox \& } \\
\text { Snell R } \\
\text { Square }\end{array}$ & $\begin{array}{l}\text { Nagelkerke R } \\
\text { Square }\end{array}$ & & & & & $\begin{array}{l}\text { Cox \& } \\
\text { Snell R } \\
\text { Square }\end{array}$ & $\begin{array}{l}\text { Nagelkerke R } \\
\text { Square }\end{array}$ & & & \\
\hline $\begin{array}{l}\text { Right ramus } \\
\text { height }\end{array}$ & $\mathrm{X}$ & 0.316 & 0.424 & 0.912 & 0.274 & 0.747 & & 0.175 & 0.235 & 0.920 & & & $\mathrm{x}$ & 0.291 & 0.389 & 0.012 & 0.328 & 0.785 \\
\hline $\begin{array}{l}\text { Left ramus } \\
\text { height }\end{array}$ & $\mathrm{x}$ & & & & 0.640 & 1.043 & & & & & & & $\mathrm{x}$ & & & & 0.637 & 1.044 \\
\hline $\begin{array}{l}\text { Right } \\
\text { mandibular } \\
\text { body length }\end{array}$ & $\mathrm{x}$ & & & & 0.476 & 0.798 & & & & & & & $\mathrm{x}$ & & & & 0.555 & 0.841 \\
\hline $\begin{array}{l}\text { Left mandibular } \\
\text { body length }\end{array}$ & $\mathrm{x}$ & & & & 0.173 & 0.854 & & & & & & & $\mathrm{x}$ & & & & 0.204 & 0.863 \\
\hline $\begin{array}{l}\text { Right effective } \\
\text { body length }\end{array}$ & $\mathrm{X}$ & & & & 0.195 & 1.537 & & & & & & & $\mathrm{X}$ & & & & 0.204 & 1.478 \\
\hline $\begin{array}{l}\text { Left effective } \\
\text { body length }\end{array}$ & $\mathrm{x}$ & & & & 0.428 & 1.049 & & & & & & & $\mathrm{X}$ & & & & 0.532 & 1.042 \\
\hline $\begin{array}{l}\text { Right condyle } \\
\text { width }\end{array}$ & $\mathrm{X}$ & & & & 0.624 & 0.943 & $\mathrm{x}$ & & & & 0.562 & 1.058 & & & & & & \\
\hline $\begin{array}{l}\text { Left condyle } \\
\text { width }\end{array}$ & $\mathrm{x}$ & & & & 0.678 & 1.051 & $\mathrm{x}$ & & & & 0.635 & 0.954 & & & & & & \\
\hline $\begin{array}{c}\text { Intergonial } \\
\text { distance }\end{array}$ & $\mathrm{x}$ & & & & 0.874 & 0.994 & & & & & & & $\mathrm{x}$ & & & & 0.384 & 1.031 \\
\hline $\begin{array}{l}\text { Mandibular } \\
\text { opening } \\
\text { distance }\end{array}$ & $\mathrm{X}$ & & & & 0.009 & 1.097 & $\mathrm{x}$ & & & & 0.000 & 1.143 & & & & & & \\
\hline $\begin{array}{l}\text { Right ramus } \\
\text { width }\end{array}$ & $\mathrm{X}$ & & & & 0.582 & 1.076 & & & & & & & $\mathrm{x}$ & & & & 0.592 & 1.072 \\
\hline Left ramus width & $\mathrm{X}$ & & & & 0.095 & 0.800 & & & & & & & $\mathrm{x}$ & & & & 0.122 & 0.819 \\
\hline $\begin{array}{l}\text { Right gonial } \\
\text { angle }\end{array}$ & $\mathrm{X}$ & & & & 0.055 & 0.671 & & & & & & & $\mathrm{x}$ & & & & 0.064 & 0.698 \\
\hline Left gonial angle & $\mathrm{x}$ & & & & 0.434 & 1.060 & & & & & & & $\mathrm{x}$ & & & & 0.415 & 1.066 \\
\hline
\end{tabular}


angle, showing that there are variances in morphology compared to the sex $[4,5,12,45]$.

Regarding age, studies, Sunar et al. (2018) studied the changes that the mandible undergoes with age and realized that the gonial angle is more obtuse in children and right in adults ( $90^{\circ}$ degrees) [25]. The present study expresses this idea since, for our age groups, mean values corresponded to an obtuse angle. The same study [25] concludes that the height and width of the ramus increase with age, which is also compatible with our study.

Despite the independent analysis of the mandible measures, it was analyzed as a tool for age range estimation regarding the Portuguese population. The goal of predictive modeling was to estimate individual age and sex from their mandible imaging data. The statistical analysis allowed us to generate a predictive model for the age group for our sample, considering all the variables under study (M1), that explains this objective with relevance (79.4\%). With all the possible associations of the variables, 3 distinct groups stood out, considering condyle variables (M3), remaining mandible (M4) and simultaneously (M2). The adjustment of the predicitive models (goodness of fit is demonstrated through the results obtained in the Omnibus test (which should be significant) and the Homer and Lemershow test (which should be non-significant), and $\operatorname{Exp}(B)>1$ values are indicative of higher predictive value of mandible measures (linear and angular).

With all the possible associations of the variables, 3 distinct groups stood out, considering condyle variables (M3), remaining mandible (M4) and simultaneously (M2).

Karlo et al. (2010) [46] reported significant age-related changes in size and shape of mandibular condyle during childhood, by 2D methodology of mandibular condyle cortication study. However, according to the present study these changes corresponded to a model (M3) with lower sensitivity (65.1\%), regarding the virtual 3D methodology used.

Our results can be explained according to the method, 2D versus $3 \mathrm{D}$, and population sample. Although our results regarding condylar morphology were relevant considering all the measures (M1).

The application of the model (s) presented in this study allows the positioning of the individual in the age group from 16 to 20 years old with the attribution of criminal imputability, in the context of the Portuguese Criminal Code [38]. Individuals over the age of 16 can be tried in a criminal court and when confirmed that a crime has been committed, they are no longer included in a program of educational guardianship measures and are now judged as adults. In a context of identification, age is complementary information, in an anthropological and forensic point of view, in living individuals or cadavers, so our study allowed us to categorize the individual in one of the age groups of our sample in line with the study of Darmawan et al. (2015) [47].

The World Health Organization highlights the impact of a multifactorial analysis in this scope of individual life. In this holistic perspective, the morphometric changes in skeletal components can be related with natural or non-pathological conditions along the individual life [21]. The scientific and standardized methodology should support statistical outcomes [29]. The present study highlighted the age variable, according to the early development of the individual, as a reference study for future analysis, during the lifetime and between different populations. Age variables become an issue with impact for clinical purpose, for diagnosis and the implementation of rehabilitation plan, as well as, for identification process, complementing the traditional and accurate methods like the fingerprint and genetic profile [1]. In extreme forensic conditions, such as fire scenarios, this identification cannot be possible and morphometric analysis is an elective alternative, allowing the comparison with antemortem clinical and imaging records [29]. The mandible as a singular bone of the human body is the correct bone to select for ID.

We can consider as limitations of the study the existence of different methods to evaluate the structural mandibular bone, without a standardization of landmarks [40]. The study material (CBCT), carried out in the living, with standardized parameterization in its acquisition (exposure times and values) made the construction of a 3D anatomical and geometric model of a human mandible a complex procedure $[28,48]$. In addition, regarding the literature cited, the characterization of the age range is older than our sample. The comparison of the present results with the literature, the lack of population data and its interpretation were a major limitation of the study.

\section{Conclusion}

In this study, 215 imagological exams and the respective 3D reconstructions obtained by CBCT were selected in the three-dimensional analysis of the mandible to characterize the biological variation of healthy individuals between 7 and 20 years of age. The mean values and standard deviation for 10 linear variables and 7 angular variables were presented, considering the influence of sex and age on the parameterization of the sample. Four predictive models of logistic regression of the age groups and one predictive model of logistic regression for the sex were presented. Considering the major outcome, it is possible to identify, with a high level of statistical significance, the individual's criminal liability regarding the medico-legal context.

\section{Declarations}

\subsection{Fundingss}

Not applicable

\subsection{Ethics approval}

$\operatorname{ref}^{\mathrm{a}} \mathrm{CE}-112 / 2019$

\subsection{Informed Consentss}

$$
\text { CE-112/2019 }
$$

\subsection{Author statement}

All the main document was changed according to R1 suggestion and "gender" was replaced by "sex" regarding to the individual biological sex.

\section{Declaration of Competing Interest}

The authors declare that they have no known competing financial interests or personal relationships that could have appeared to influence the work reported in this paper.

\section{Acknowledgement}

The authors would like to thank all the intervenient of this study; to the Laboratory of Forensic Dentistry and to the Anatomy Institute.

\section{References}

[1] Corte-Real, A. and D.N. Vieira, Identificação em Medicina Dentária Forense. 2015, Coimbra: Imprensa da Universidade de Coimbra.

[2] Schmitt, A., E. Cunha, and J. Pinheiro, Forensic Anthropology and Medicine. Complementary Sciences from recovery to cause of death. 2006, New Jersey: Humana Press.

[3] I. Sierp, M. Henneberg, The difficulty of sexing skeletons from unknown populations, J. Anthropol. 2015 (2015) 1-13.

[4] C. Gillet, L. Costa-Mendes, C. Rérolle, N. Telmon, D. Maret, F. Savall, Sex estimation in the cranium and mandible: a multislice computed tomography (MSCT) study using anthropometric and geometric morphometry methods, Int. J. Legal Med. 134 (2) (2020) 823-832.

[5] T.S. Tunis, R. Sarig, H. Cohen, B. Medlej, N. Peled, H. May, Sex estimation using computed tomography of the mandible, Int. J. Legal Med. 131 (6) (2017) 1691-1700. 
[6] F. Ramsthaler, M. Kettner, A. Gehl, M.A. Verhoff, Digital forensic osteology: morphological sexing of skeletal remains using volume-rendered cranial CT scans, Forensic Sci. Int. 195 (1-3) (2010) 148-152.

[7] Berg, G.E. and M.W. Kenyhercz, Introducing Human Mandible Identification [(hu) MANid]: A Free, Web-Based GUI to Classify Human Mandibles. Journal of Forensic Sciences, 2017. 62(6): p. 1592-1592 - 1598.

[8] A. Forrest, Forensic odontology in DVI: current practice and recent advances, Foren. Sci. Res. 4 (4) (2019) 316-330.

[9] E. Nguyen, E. Doyle, Dental post-mortem computed tomography for disaster victim identi fi cation: a literature review, J. Forensic Radiol. Imaging 13 (2018) 5-11.

[10] S. Motawei, et al., Length of the ramus of the mandible as an indicator of chronological age and sex: a study in a group of Egyptians, Forensic Sci. Int. Rep. 2 (2020).

[11] A. Cappella, D. Gibelli, A. Vitale, M. Zago, C. Dolci, C. Sforza, C. Cattaneo, Preliminary study on sexual dimorphism of metric traits of cranium and mandible in a modern Italian skeletal population and review of population literature, Leg. Med. 44 (2020) 101695, https://doi.org/10.1016/j.legalmed.2020.101695.

[12] C.S. Yuvashree, Morphological and morphometric analysis of mandible bone for determination of sex, J. Pharm. Res. 10 (1) (2018) 2813-2816.

[13] S. Standring, Gray's, Anatomy. The Anatomical Basis of Clinical Practice, 40th ed., Churchill Livingstone, United Kingdom, 2008.

[14] V. Saini, et al., Mandibular ramus: an indicator for sex in fragmentar mandible, J. Forensic Sci. 56 (2011) 13-16.

[15] Elisabeth Nicholson, Katerina Harvati, Quantitative analysis of human mandibular shape using three-dimensional geometric morphometrics, Am. J. Phys. Anthropol. 131 (3) (2006) 368-383.

[16] D. Liberton, et al., Development and validation of novel three-dimensional craniofacial landmarks on cone-beam computed tomography scans, J. Craniof. Surg. 30 (7) (2019) 611-615.

[17] Daniel Franklin, Andrea Cardini, Paul O’Higgins, Charles E. Oxnard, Ian Dadour, Mandibular morphology as an indicator of human subadult age: geometric morphometric approaches, Forensic Sci. Med. Pathol. 4 (2) (2008) 91-99.

[18] Carla R. Moreira, Marcelo A.O. Sales, Patricia M.L. Lopes, Marcelo G.P. Cavalcanti, Assessment of linear and angular measurements on threedimensional cone-beam computed tomographic images, Oral Surg. Oral Med. Oral Pathol. Oral Radiol. Endod. 108 (3) (2009) 430-436.

[19] Jelena Mitic, Nikola Vitkovic, Miodrag Manic, Miroslav Trajanovic, Sladjana Petrovic, Stojanka Arsic, Reverse modeling of the human mandible 3D geometric model, Vojnosanit Pregl 77 (3) (2020) 262-270.

[20] B. Hassan, P. Nijkamp, H. Verheij, J. Tairie, C. Vink, P. van der Stelt, H. van Beek, Precision of identifying cephalometric landmarks with cone beam computed tomography in vivo, Eur. J. Orthod. 35 (1) (2013) 38-44.

[21] J.B. Ludlow, et al., Precision of cephalometric landmark identification: Cone-beam computed tomography vs conventional cephalometric views, Am. J. Orthod. Dentofac. Orthop. 136 (3) (2009) 1-10.

[22] Z. Gao, et al., A novel geometric morphometric analytical method for classifying mandibular morphology in infants with isolated Pierre Robin sequence, J. Oral Maxillofac. Surg. 19 (2020) 1-36.

[23] A. Giudice, S. Barone, K. Belhous, A. Morice, V. Soupre, F. Bennardo, N. Boddaert, M.-P. Vazquez, V. Abadie, A. Picard, Pierre Robin sequence: a comprehensive narrative review of the literature over time, J. Stomatol. Oral Maxillof. Surg. 119 (5) (2018) 419-428.

[24] F. Apolloni, et al., Mandible customized distraction osteogenesis in Treacher Collins patient: Literature review, report of a case and post-distraction analysis, Interdiscipl. Neurosurgery 21 (2020) 1-6.

[25] S. Sunar, M.S. Thenmozhi, A study on the age changes of mandible, Drug Invention Today 10 (12) (2018) 2345-2348.

[26] R. Drake, W. Vogl, A. Mitchell, Gray's Anatomy for students, 2nd ed., Churchill Livingstone Elsevier, Philadelphia, 2010.

[27] Joe Iwanaga, R. Shane Tubbs (Eds.), Anatomical Variations in Clinical Dentistry, Springer International Publishing, Cham, 2019.
[28] Stefan Raith, Viktoria Varga, Timm Steiner, Frank Hölzle, Horst Fischer, Computational geometry assessment for morphometric analysis of the mandible, Comput. Methods Biomech. Biomed. Eng. 20 (1) (2017) 27-34.

[29] Corte-Real, A., et al., Cone Beam Computed Tomography (CBCT) Technology and Learning Outcomes in Dental Anatomy Education: E-Learning Approach. Anatomical Sciences Education, 2021.

[30] Chung, M.T., et al., Pierre Robin Sequence and Treacher Collins Hypoplastic Mandible Comparison Using Three-Dimensional Morphometric Analysis. Journal of Craniofacial Surgery, 2012. 23: p. 17-21.

[31] Bong Chul Kim, Helios Bertin, Hak-Jin Kim, Sang-Hoon Kang, Jacques Mercier, Jean-Philippe Perrin, Pierre Corre, Sang-Hwy Lee, Structural comparison of hemifacial microsomia mandible in different age groups by three-dimensional skeletal unit analysis, J. Craniomaxillofac. Surg. 46 (11) (2018) 1875-1882.

[32] Vallabh, R., et al., The morphology of the human mandible: A computational modelling study Biomechanics and Modeling in Mechanobiology, 2019.

[33] Ana Corte-Real, Renata Mayumi Kato, Tiago Nunes, Francisco Vale, Daniela Garib, Reproducibility of mandibular landmarks for three-dimensional assessment, Forensic Sci. Int. Rep. 2 (2020) 100144, https://doi.org/10.1016/j. fsir.2020.100144.

[34] Calogero Dolce, Susan P. McGorray, Lisamarie Brazeau, Gregory J. King, Timothy T. Wheeler, Timing of class II treatment: skeletal changes comparing 1-phase and 2-phase treatment, Am. J. Orthod. Dentofacial. Orthop. 132 (4) (2007) 481-489.

[35] L.F. Martinez, A. Ferreira, Análise de Dados Com SPSS Primeiros Passos, Lisboa, Escolar Editora, 2010.

[36] Pallant, J., SPSS Survival Manual A Step By Step Guide to Data Analysis Using SPSS Program. 2016, London, UK: McGraw-Hill Education.

[37] Seetala Sanggarnjanavanich, Toshiko Sekiya, Yoshiaki Nomura, Takahiro Nakayama, Nobuhiro Hanada, Yoshiki Nakamura, Cranial-base morphology in adults with skeletal Class III malocclusion, Am. J. Orthod. Dentofac. Orthop. 146 (1) (2014) 82-91.

[38] Nutrição, A.P.d., A Educação Alimentar Em Meio Escolar E A Figura Do Nutricionista Escolar. Acta Portuguesa De Nutrição, 2020.

[39] D. Lopes da Silva, et al., Síndrome de Treacher Collins: Revisão de Literatura, Intl Arch. Otorhinolaryngol. 12 (2008) 116-121.

[40] Chang, C.C. and D.M. Steinbacher, Treacher Collins Syndrome. Semin Plast Surg, 2012. 26: p. 83-90.

[41] R. Silva, et al., Revisão bibliográfica sobre a sindrome de treacher collins: descrições embriológicas e fenotípicas, Cadernos de Graduação 4 (2018) 27-34.

[42] A, G., et al., The use of three-dimensional reconstructions of CT scans to evaluate anomalies of hyoid bone in Pierre Robin sequence: A retrospective study. $\mathrm{J}$ Stomatol Oral Maxillofac Surg, 2019. 743: p. 1-6.

[43] P.-L. Westesson, et al., Radiographic assessment of asymmetry of the mandible, Am. J. Neuroradiol. 15 (1994) 991-999.

[44] Y. Fan, et al., Quantification of mandibular sexual dimorphism during adolescence, J. Anat. (2019) 1-8.

[45] Amina, D. Othmana, Gender dimorphism of crania in young jordanian adults: discriminant function analysis approach for gender prediction, J. Curr. Surg. 4 (2014) 78-85.

[46] Christoph A. Karlo, Paul Stolzmann, Sandra Habernig, Lukas Müller, Traudel Saurenmann, Christian J. Kellenberger, Size, shape and age-related changes of the mandibular condyle during childhood, Eur. Radiol. 20 (10) (2010) 2512-2517.

[47] M.F. Darmawan, Suhaila M. Yusuf, M.R. Abdul Kadir, H. Haron, Age estimation based on bone length using 12 regression models of left hand X-ray images for Asian children below 19 years old, Leg. Med. 17 (2) (2015) 71-78.

[48] Ay, M.K., Tinaz Delilbasic, Cagri Ekicid, Bulent Emir Yuzbasioglue, Huseyin and S. Hartomacioglub, 3D Bio-Cad modeling of human mandible and fabrication by rapid-prototyping technology. Usak University Journal of Material Sciences, 2013. 2: pp. $135-145$. 